\title{
CONFORTO E DURABILIDADE DE PROTÓTIPOS DE CALÇAS DE JEANS CO/PET CONVENCIONAL E DE JEANS CO/PET RECICLADO
}

\author{
Luciana dos Santos Duarte \\ Faculdades Kennedy \\ santosduarte.luciana@gmail.com
}

\begin{abstract}
Resumo: O jeans é um material central na cultura humana. Cada vez mais são ofertados jeans compostos de CO/PET convencional, devido às vantagens competitivas de sua produção. Buscando minimizar o impacto ambiental gerado por este tipo de jeans, a indústria têxtil tem ofertado jeans de fibras recicladas. A substituição de um jeans pelo outro, por parte do consumidor, está sujeita, contudo, a uma investigação sobre a adequação ao uso, à durabilidade da matéria-prima empregada e aos critérios ecológicos e de qualidade. A durabilidade e o conforto dos jeans supracitados são analisados comparativamente por meio de teste de uso de dois protótipos de calças, que foram lavados de forma intensiva, durante 30 dias cada. A avaliação do uso dos protótipos indica que ambos, por terem a mesma composição, apresentam conforto termo-fisiológico semelhantes. Nos demais parâmetros apresentados, o jeans CO/PET convencional apresenta maior conforto tátil e conforto estético que o jeans reciclado, sendo preferível do ponto de vista do usuário. As informações fornecidas pelos fabricantes permitiram constatar que o jeans CO/PET convencional comporta maior amplitude de formas de lavar, passar e secar - ao contrário do jeans reciclado. De uma maneira geral, embora o jeans reciclado esteja associado à redução do impacto ambiental nas fases de pré-produção à manutenção, o mesmo apresenta menor durabilidade e conforto que em relação ao jeans CO/PET convencional.
\end{abstract}

Palavras-chave: Conforto de jeans, calça jeans, jeans reciclado, jeans CO/PET, teste de uso

\begin{abstract}
Jeans is a core material in human culture. Increasingly, conventional CO/PET jeans are offered due to the competitive advantages of its production. Seeking to minimize the environmental impact generated by this type of jeans, the textile industry has offered recycled jeans. The replacement of one jeans for the other, by the consumer, is subject to an investigation of the fitness for use, the durability of the raw material used and the ecological and quality criteria. The durability and comfort of the aforementioned jeans are comparatively analyzed by using two prototype
\end{abstract}


pants, which have been washed intensively for 30 days each one. The evaluation of the use of the prototypes indicates that since both of them have the same composition, they have similar thermo-physiological comfort. For the other parameters presented, the CO/PET conventional jeans has greater tactile comfort and aesthetic comfort that recycled jeans, being preferable from the point of view of the user. The information provided by the manufacturers showed that CO/PET conventional jeans PET involves greater range of ways of washing, ironing and dry - unlike the recycled jeans. In general, although the recycled jeans are associated with reduced environmental impact from the pre-production to maintenance, it has lower durability and comfort compared to CO/PET conventional jeans.

Keywords: Jeans comfort, jeans pants, recycled jeans, CO/PET jeans, usability test

\section{INTRODUÇÃO}

O aumento da população mundial com acesso a bens de capital, a consolidação de uma sociedade de consumo, as empresas incrementando a produtividade para suprir tais demandas de consumo, a consequente escassez de recursos naturais, além da ampla emissão de poluentes no meio ambiente são preocupações consensuais diante do paradigma ambiental. Também é de comum interesse o presente momento de conscientização ambiental e a pressão por parte de organismos ambientais, da mídia em geral, de grupos ambientalistas e de consumidores questionadores por processos produtivos mais limpos e produtos ecológicos. Incontáveis e diversos trabalhos acadêmicos abordam tais temas (BOVEA e PÉREZ-BELIS, 2012; CLARCK et al, 2009; KAZAZIAN, 2005; LEITE, 2009; SELIG et al, 2008; SLACK et al, 1997). Nesse contexto, a indústria têxtil enfrenta uma condição desafiadora no campo da qualidade e da produtividade. Conforme os parâmetros ecológicos têm se tornado mais rigorosos e altamente competitivos, surgiu uma preocupação da indústria têxtil com relação à necessidade de conjugar a qualidade e a ecologia conjuntamente (BOTA e RATIU, 2008).

Pode-se dizer que a sustentabilidade - considerando suas cinco dimensões propostas por SACHS (1993), social, econômica, ecológica, espacial e cultural - é possivelmente a maior crítica que a cadeia têxtil e de confecções (TC) já enfrentou, pois desafia a moda em seus detalhes (fibras e processos) e também com relação ao todo (modelos econômicos, metas, regras, sistemas de crenças e valores) (FLETCHER e GROSE, 2011). No que concerne ao setor têxtil, a produção e o produto têxteis são relacionados com o paradigma da sustentabilidade ambiental em vários estudos científicos (ABREU et al, 2008; COMAN et al, 2011; FLETCHER e GROSE, 2011; KALLIALA e NOUSIAINEN, 1999; LEÃO et al, 2002; SOUZA, 2000; RUSU, 2010), para os quais este trabalho busca contribuir.

No rol dos produtos têxteis mais manejados pelo homem, encontra-se o jeans, material vestido por todos, sem limite de idade, sexo e cultura (CATOIRA, 2006). A rigor, o jeans é o resultado da união do tecido denim com o corante índigo. $O$ denim surgiu em 1567, na França, e logo se tornou reconhecido por sua resistência superior aos demais tecidos. Inicialmente, o denim foi usado nas velas de embarcações 
mercantis e, no século XIX, passou a ser usado no vestuário de marinheiros genoveses e de mineradores americanos (PEZZOLO, 2007). Em 1853, Levi Strauss uniu o tecido denim, de algodão, com o corante índigo, criando o blue jeans. Em 1860, as calças jeans, duráveis e confortáveis, começaram a substituir as de lona, tornando-se traje obrigatório entre os mineradores norte-americanos, sendo em seguida apropriado por cowboys e lenhadores. Em 1877, as calças jeans ganharam rebites nos bolsos, originando o clássico jeans Levi's 501, que logo foi patenteado por Levi Strauss.

No início do século $X X$, o jeans ainda era só um tecido forte usado por homens em local de trabalho rude (CATOIRA, 2006), ou seja, sua durabilidade estava associada ao uso profissional e não ao de moda. No Brasil, na relação de tecidos produzidos pela Companhia de Fiação e Tecidos Cedro e Cachoeira (empresa privada mais antiga do Brasil), em 1897, não constava jeans ou denim, apenas similares, como brim lona, brim mineiro, brim mineiro xadrez e brim angola (GIROLETTI, 1991).

Enquanto o boom do jeans, em todas as classes e idades, se deu na segunda metade do século XX no mundo (LIPOVETSKY, 2009), o jeans somente começou a ganhar massivamente o mercado brasileiro em 1970, tendo uma aceitação natural inicialmente pela juventude (CATOIRA, 2006). Pode-se dizer que, a partir dos anos 1950, a humanidade passou a se vestir de azul índigo com maior frequência. $O$ índigo, considerado o corante mais antigo para tingir tecidos, data de 3.000 a.C. e provinha de plantas do gênero Indigofera. Mercadoria de grande valor, o intenso azul somente chegou à Europa mercantil em 1516 (PEZZOLO, 2007), tendo sido obtido sinteticamente em 1880. O índigo é possivelmente o corante e a cor mais comum da moda, apresentando tonalidades e matizes de azul multiplicados pelos beneficiamentos de lavanderia a que é submetido o vestuário em jeans (jeanswear). Em consequência à popularidade do blue jeans e ao respectivo apreço pela cor azul, o consumo atual do corante índigo é enorme (MEKSI et al, 2012).

A centralidade do jeans na cultura material, somada à sua respectiva portentosa produção destinada a suprir demandas mundiais de vestuário, produz um rebatimento em diversas cadeias produtivas, da cotonicultura e petroquímica, passando pelas de maquinário e confecções, até chegar às de reciclagem de resíduos têxteis e poliméricos. Tradicionalmente, a calça jeans comum é geralmente feita de 100\% algodão convencional (BILISIK e YOLACAN, 2011), não-orgânico. No entanto, também são cada vez mais ofertados jeans com fibras de até $3 \%$ de elastano, e com diversos percentuais de fibra de poliéster (PET), ambas derivadas do petróleo, recurso natural não-renovável. Por conseguinte, o jeans implica em uma alta carga de impacto ambiental associada a sua manufatura, bem como ao seu uso e manutenção. Entretanto, é cada vez maior a oferta de jeans composto de CO/PET convencional, devido às vantagens de baixo custo da fibra de poliéster e ao fato de que seu acréscimo ao algodão permite maior rapidez na produção têxtil.

Buscando minimizar tal impacto ambiental gerado pelo jeans CO/PET convencional, a indústria têxtil tem ofertado jeans de fibras recicladas. A substituição de um jeans pelo outro, por parte do consumidor, está sujeita, contudo, a uma investigação sobre a adequação ao uso, à durabilidade da matéria-prima empregada e aos critérios ecológicos e de qualidade que norteiam a configuração de um jeans convencional e de um jeans reciclado. Tais tipos de jeans são, portanto, comparáveis quanto à durabilidade do tecido propriamente. 
A durabilidade e o conforto dos dois tipos de jeans supracitados são analisados comparativamente por meio de teste de uso de protótipos de calças. Com a finalidade de observar o comportamento dos materiais com o desgaste do uso cotidiano, foram confeccionados dois protótipos de calças jeans e usados e lavados de forma intensiva, durante 30 dias cada protótipo. O desenvolvimento e os testes de uso são mostrados a seguir, assim como ao final os resultados obtidos.

\section{DESENVOLVIMENTO}

Pode-se dizer que o desgaste do jeanswear é positivo para que o mesmo seja apreciado pelos usuários, sendo o uso e as lavagens intensivas desejáveis, não fosse pela questão do impacto ambiental gerado na manutenção do vestuário. De acordo com HU (2012), pouco tem sido estudado sobre inovações em design na fase de uso das roupas, esta considerada uma área sub explorada na moda sustentável. Tendo como foco a sustentabilidade ambiental na fase de uso/manutenção do vestuário, foi proposta a lavagem de baixo impacto, considerando os fatores de temperatura de lavagem, frequência de lavagem e quantidade de carga (HU, 2012), que devem ser reduzidos.

A friç̧ão na superfície do tecido aumenta com as lavagens sucessivas (VIVEKANADAN et al, 2011) e com o uso constante, o que tem como resultados: diminuição da rugosidade do tecido, estiramento do tecido e desbote da cor. Em tese, tais resultados são inevitáveis uma vez que o jeanswear é destinado ao uso diário, e não para situações especiais e esporádicas. Sabendo que o jeans, quanto mais gasto e usado se torna, mais é apreciado (FLETCHER, 2008). De fato, o jeanswear recebe beneficiamentos de lavanderia que simulam desgastes de uso, como puídos, manchas e desbote, não sendo comercializados com pilling. Em contrapartida, o jeans é uma roupa que suja pouco, que pode ser usada nas circunstâncias mais variadas, que não exige uso constante de ferro nem limpeza meticulosa, que suporta o desgaste, o desbotado, o rasgado (LIPOVETSKY, 2009).

A cor é um dos aspectos mais vitais e visualmente estimulantes da moda (FLETCHER e GROSE, 2011; COBRA, 2007) e, não obstante, o azul escuro trata-se de uma cor com qualidades próximas a do preto, como ser elegante e adequada para todas as horas, idades e ocasiões (DIOR, 2009). Diferentemente de outros tipos de tingimento, o tingimento com índigo não tem muita afinidade com o algodão, caracterizando-se por ser superficial, isto é, ele não preenche todo o fio, formando uma espécie de anel azul em torno de um núcleo branco (FIG. 01). Assim, a solidez do índigo no tecido é mais baixa ao atrito, ou seja, ao sofrer abrasão, o tecido perde sua camada superficial de fibras e, com isso perde sua cor, caracterizando o efeito de desbote do jeans. 




FIGURA 01 - Fio 100\% algodão, tingido com índigo, mantendo o núcleo branco. Fonte: FIGUEIREDO e CAVALCANTE, 2010, p. 130.

\subsection{Desenvolvimento dos protótipos das calças jeans}

De acordo com BAXTER (2000), o protótipo geralmente é construído com os mesmos materiais do produto final e tem os mecanismos necessários que o fazem funcionar. Dessa forma, são usados nos testes funcionais de avaliação do produto. Foram desenvolvidos dois protótipos de calças, cada um com um dos tipos de jeans analisados, com o objetivo de obter dados sobre o desgaste sofrido pelo uso e lavagem domésticos e consecutivos, ou seja, obter dados sobre os materiais usados.

Embora não tenham sido encontrados estudos sobre a duração do ciclo de uso de vestuário no Brasil, uma pesquisa na Noruega mostra que as peças de roupa são usadas 44 vezes durante sua vida útil e são lavadas 25 vezes pelas mulheres norueguesas. O tempo de vida médio das roupas é de sete anos, incluindo o tempo em que as mesmas ficam estocadas no guarda-roupa sem uso (LAITALA e BOKS, 2012). Para uma ACV de uma blusa de poliéster, foi determinado que a mesma, durante sua vida útil, seria usada 40 vezes e lavada 20 vezes (SMITH e BARKER, 1995). Em geral, estima-se que um vestuário típico só é secado e lavado por volta de 20 vezes durante sua vida (HU, 2012). Baseando-se nesses estudos, bem como considerando a finalidade de uso casual e intenso do jeans no contexto brasileiro, foram estabelecidos para este trabalho o número de 30 dias de uso e a quantidade de 30 lavagens para cada tipo de calça, em um período intensivo de 60 dias.

Foram selecionados dois tipos de jeans para este trabalho, descritos a seguir e apresentados conforme a TAB. 01.

TABELA 01 - Relação dos produtos têxteis investigados neste trabalho.

\begin{tabular}{c|c|c|c|c}
\hline Amostra & Fibras recicladas & $\begin{array}{c}\text { Fibras } \\
\text { convencionais }\end{array}$ & Gramatura / $\mathbf{m}^{\mathbf{2}}$ & $\begin{array}{c}\text { Percentual de } \\
\text { encolhimento }\end{array}$ \\
\hline $\begin{array}{c}\text { Jeans } \\
\text { Convencional }\end{array}$ & - & $\begin{array}{c}78 \% \mathrm{CO} / \\
22 \% \mathrm{PET}\end{array}$ & $295 \mathrm{~g}$ & $\begin{array}{c}2 \% \text { na trama } \\
2 \% \text { no urdume }\end{array}$ \\
\hline Jeans reciclado & $80 \% \mathrm{CO} /$ & - & $284 \mathrm{~g}$ & $3 \%$ na trama \\
& $20 \% \mathrm{PET}$ & & & $3 \%$ no urdume \\
\hline
\end{tabular}

Fonte: dados fornecidos pelos fabricantes.

O jeans CO/PET convencional é composto de dois tipos de fibras, sendo $78 \%$ delas de algodão convencional e tinto de índigo, no sentido do urdume (fios no sentido 
vertical do tecido), e as demais de poliéster virgem, no sentido da trama (fios horizontais). Já o jeans reciclado se trata de um jeans composto por fios formados por $80 \%$ de fibras de algodão desfibrado reciclado e previamente tingido, juntamente a $20 \%$ de fibras de poliéster reciclado de garrafas. Neste caso, as fibras misturam-se formando um único fio, uma blenda, que é usado tanto no sentido da trama quanto do urdume.

Inicialmente, os tecidos ficaram de molho em água durante 24 horas. Essa prática é necessária para que possíveis substâncias, tais como gomas e tintas, se desprendam do tecido, tornando-o mais maleável, além de permitir que o tecido sofra encolhimento. Em seguida, foi determinado o tamanho para confecção da calça, como sendo o 40 que, assim como o 42, é padrão em protótipos para empresas de moda vestuário que trabalham com grade numérica (assim como o $\mathrm{P}$ ou $\mathrm{M}$ são padrão em empresas que usam esse tipo de graduação). Como configuração da calça, foi utilizado um modelo básico, slim (cujo ajuste às pernas fica entre o apertado modelo skinny e a calça reta) de uma calça jeans produzida por uma grande empresa brasileira especializada em vestuário casual e popular. Dado que o protótipo deve ter o mínimo grau de complexidade e sofisticação, o necessário apenas para se obter a resposta que procura (BAXTER, 2000), os bolsos frontais foram retirados no novo modelo para facilitar a confecção.

Depois de tirado o molde em papel e cortado o jeans CO/PET convencional, foi alinhavado o primeiro protótipo para a etapa de prova de roupa, na qual são feitos ajustes ao corpo do usuário cujas medidas do manequim correspondem às dos protótipos. Foram feitos ajustes nos joelhos e nos quadris, subtraindo medidas na largura - os ajustes nessas localidades do corpo são comuns quando se copia uma roupa já usada, pois as roupas estão principalmente sob tensão nessas partes (OZDIL, 2008), ocasionando o estiramento do tecido em tais regiões. Com base no molde resultante dos novos ajustes, foi feita a calça de jeans reciclado (FIG. 02). As calças foram costuradas em uma máquina reta industrial e em uma máquina overlock. Foi observado que o jeans reciclado se mostrou mais maleável que o jeans CO/PET convencional ao ser costurado.

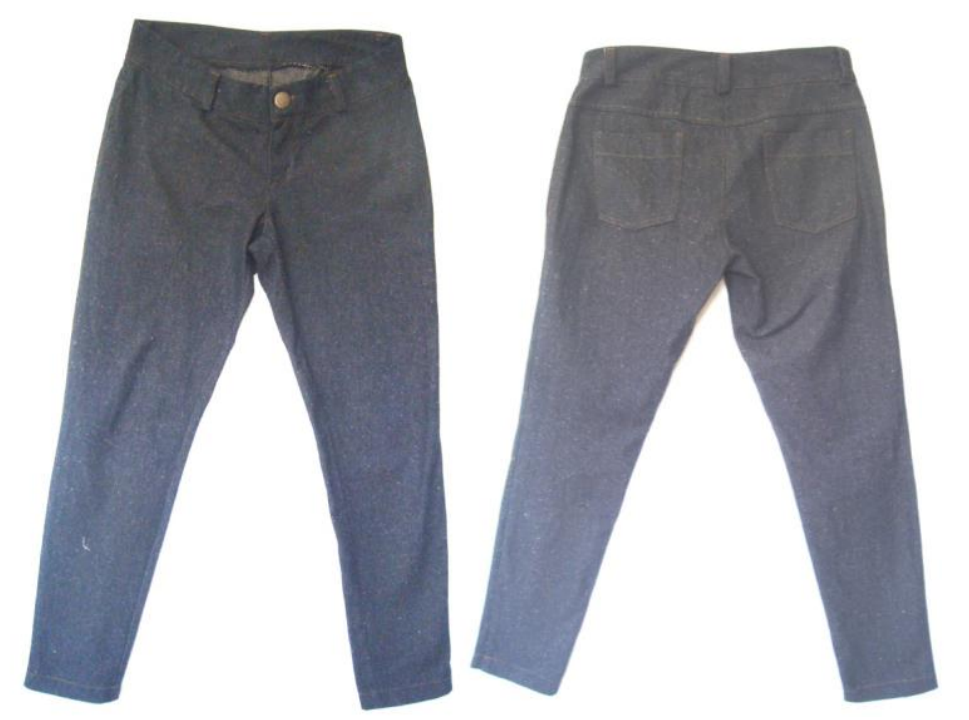

FIGURA 02 - Protótipo da calça em jeans reciclado, modelo slim, sem bolsos frontais. Elaborado pela autora, com base na pesquisa realizada. 


\subsection{Avaliação do uso dos protótipos}

De acordo com CALLISTER (2002), a facilidade de lavar e conservar os tecidos, cujas fibras são poliméricas, depende de as fibras exibirem estabilidade química a uma variedade considerável de ambientes, incluindo também ácidos, bases, alvejantes, solventes de lavagem a seco e à luz do sol. Além disso, elas devem ser relativamente não-inflamáveis e suscetíveis à secagem. Considerando o código de cuidados para têxteis usando símbolos, conforme a ABNT NBR ISO 3758 (2006), as empresas fornecedoras esclarecem que os materiais requerem diversos cuidados de modo que os mesmos tenham o maior ciclo de uso possível. Tais cuidados e símbolos foram sumarizados em critérios para os materiais em questão conforme TAB. 02.

TABELA 02 - Critérios de cuidados dos materiais para que tenham maior ciclo de uso.

\begin{tabular}{|c|c|c|}
\hline Critério & $\begin{array}{l}\text { Jeans CO/PET } \\
\text { Convencional }\end{array}$ & $\begin{array}{l}\text { Jeans CO/PET } \\
\text { Reciclado }\end{array}$ \\
\hline Temperatura de lavagem & Até $60^{\circ} \mathrm{C}$ & Até $40^{\circ} \mathrm{C}$ \\
\hline Tipo de ferro para passar & Normal & A vapor \\
\hline Temperatura máxima para passar a ferro & Até $150^{\circ} \mathrm{C}$ & Até $110^{\circ} \mathrm{C}$ \\
\hline Secagem & $\begin{array}{l}\text { Permitida secadora à } \\
\text { temperatura máxima de } \\
65^{\circ} \mathrm{C}\end{array}$ & $\begin{array}{l}\text { Não deve ser secado em } \\
\text { tambor. Deve ser secado } \\
\text { na sombra. }\end{array}$ \\
\hline $\begin{array}{l}\text { Lavagem com produtos que contenham } \\
\text { cloro (alvejamento) }\end{array}$ & Não permite & Não permite \\
\hline Lavagem a seco & Permite & Não permite \\
\hline $\begin{array}{l}\text { Tipo de processo de limpeza a úmido } \\
\text { profissional }\end{array}$ & Normal & Suave \\
\hline
\end{tabular}

Fonte: dados fornecidos pelos fabricantes.

Nota-se que o jeans reciclado exige cuidados mais restritos que em relação ao jeans CO/PET convencional. Apesar dessas diferenças, no que concerne aos cuidados durante o teste de uso, as calças receberam o mesmo tratamento, tendo sido lavadas à mão em temperatura de lavagem ambiente, secadas à sombra e passadas com ferro seco, em dias alternados.

Segundo CHATTOPADHYAY (2008), tanto os aspectos funcionais quanto os aspectos estéticos são importantes. Enquanto aqueles podem ser mensurados por parâmetros objetivos, estes se relacionam com critérios subjetivos, baseando-se no julgamento dos sentidos do corpo humano. BAXTER (2000) afirma que ao se examinar a interface homem-produto em detalhe, pode-se descobrir que ela geralmente é complexa, além de pouco compreendida, até mesmo nos casos mais simples. A análise de uma tarefa, como usar calças jeans, explora as interações entre o produto e seu usuário através de observações e análises. Conforme VIVEKANADAN et al (2011), a interação entre roupas e o corpo humano estimula sensações mecânicas, visuais e térmicas. IIDA (2005) define sensação como o processo biológico de captação de energia ambiental, isto é, a energia é captada por células nervosas e convertida em um impulso eletroquímico. Tais sensações conduzem a uma percepção de conforto ao usar a roupa. A percepção, por sua vez, é definida como o resultado do processamento do estímulo sensorial, dando-lhe um significado (IIDA, 2005). Desse modo, avaliar a usabilidade dos protótipos das calças jeans depende da percepção de conforto resultante do uso. O conforto das roupas pode ser compreendido como um fenômeno 
de múltiplos critérios que requerem satisfação simultânea dos mesmos (PORAV e DOBLE, 2010). Por definição, o conforto das roupas é um estado agradável resultante da harmonia entre o fisiológico, o psicológico e físico (VIVEKANADAN et al, 2011). PORAV e DOBLE (2010) classificam o conforto das roupas em três categorias: a) conforto estético, b) conforto termo-fisiológico, c) conforto tátil (FIG. 03).

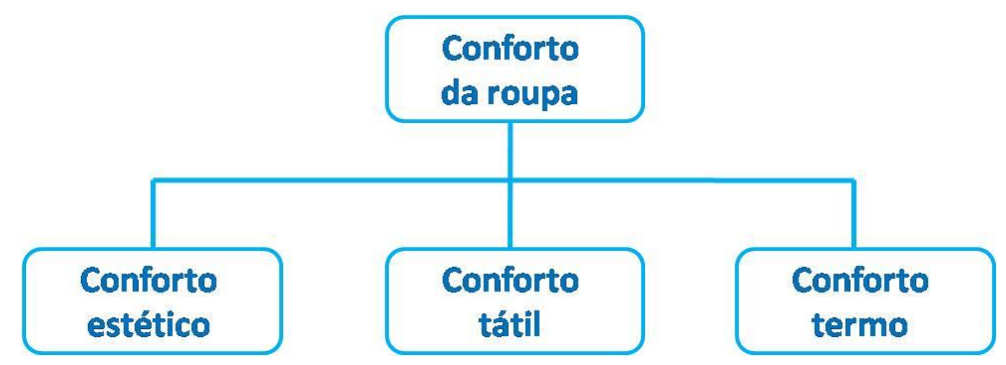

FIGURA 03 - Classificação do conforto das roupas.

Adaptado de PORAV e DOBLE (2010).

Com base nessa classificação, foram considerados como parâmetro de usabilidade para avaliar os protótipos: a percepção visual e a percepção tátil. Ressaltase que o fator termo-fisiológico não tem peso para esta avaliação, uma vez que ambos os jeans possuem praticamente a mesma composição de fibras de algodão e poliéster. BERTINI (2003) analisou a transferência térmica de três produtos têxteis de acordo com sua composição: 1) $100 \%$ algodão, 2) $67 \%$ algodão e $33 \%$ poliéster, 3) $33 \%$ algodão e $67 \%$ poliéster. Nos quesitos permeabilidade ao vapor d'água e isolamento térmico, por exemplo, os tecidos $100 \%$ algodão apresentaram melhor desempenho em relação aos demais. De fato, a composição equivalente dos jeans estudados implica em um conforto termo-fisiológico semelhante para ambos.

No que concerne ao conforto tátil, PORAV e DOBLE (2010) afirmam que o mesmo está relacionado à interação mecânica entre o material da roupa e o corpo humano, o que é uma performance essencial e intrínseca, requerida nas roupas. Logo, o conforto tátil relaciona-se com a superfície do tecido e propriedades mecânicas. Ao final do período estabelecido para o teste de uso, observou-se que a calça de jeans reciclado apresentou um estiramento superior que a calça de jeans CO/PET convencional, o qual praticamente não apresentou deformação.

O conforto estético, por sua vez, baseia-se principalmente em percepções subjetivas e tendências de moda que influenciam as preferências dos consumidores. Ele inclui critérios como tamanho, forma, cor, brilho, estilo, estar de acordo com tendências de moda, etc. (PORAV e DOBLE, 2010). O aspecto visual do jeans das calças após o uso demonstrou diferenças consideráveis que influenciam no conforto estético. A FIG. 04 mostra os jeans antes de serem confeccionados, já a FIG. 05 apresenta o aspecto visual dos jeans depois de usados e lavados durante 30 dias cada.

Comparando uma figura com a outra, é possível observar que o jeans reciclado apresentou um aspecto "aveludado", em função das fibras que se desprenderam no tecido ao final do teste de uso. A calça de jeans CO/PET convencional não apresentou emaranhamento das fibras visível a olho nu. Já a calça de jeans reciclado, apresentou a formação de pilling (principalmente na região do entre pernas), embora não se possa afirmar de qual grau sem submeter os tecidos ao ensaio propriamente. O resultado é, 
portanto, desfavorável ao conforto estético do jeans reciclado, pois a formação de pilling não é uma característica apreciada em roupas.

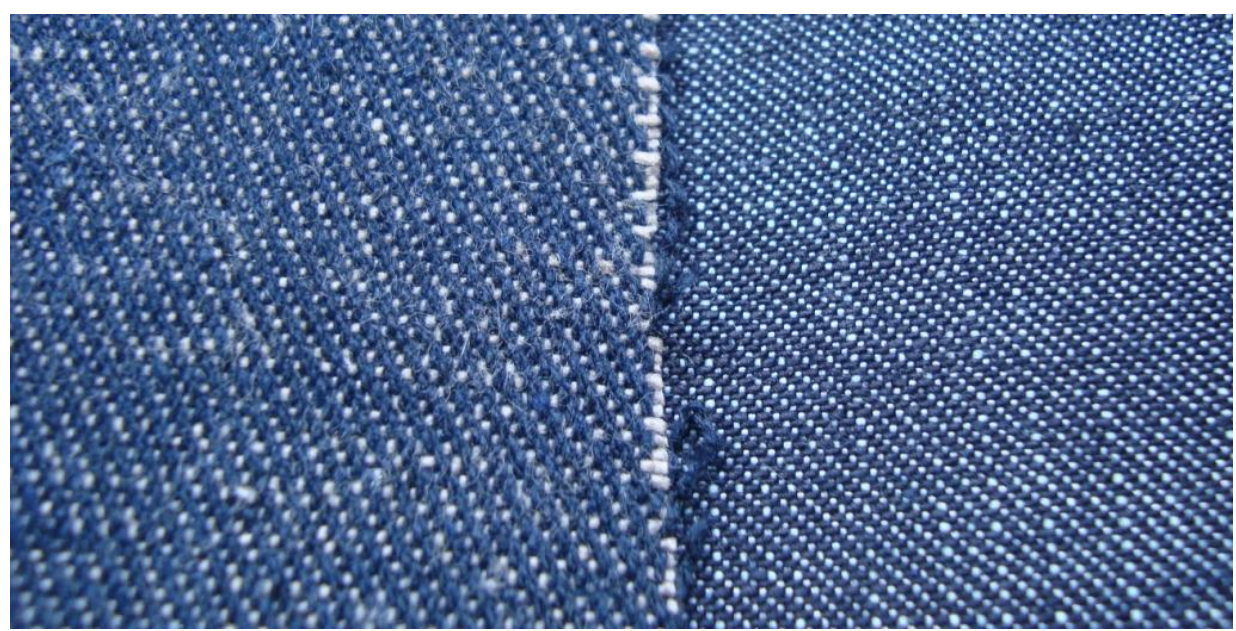

FIGURA 04 - Jeans reciclado (à esq.) e jeans convencional (à dir.) antes de serem confeccionados. Elaborado pela autora, com base na pesquisa realizada.

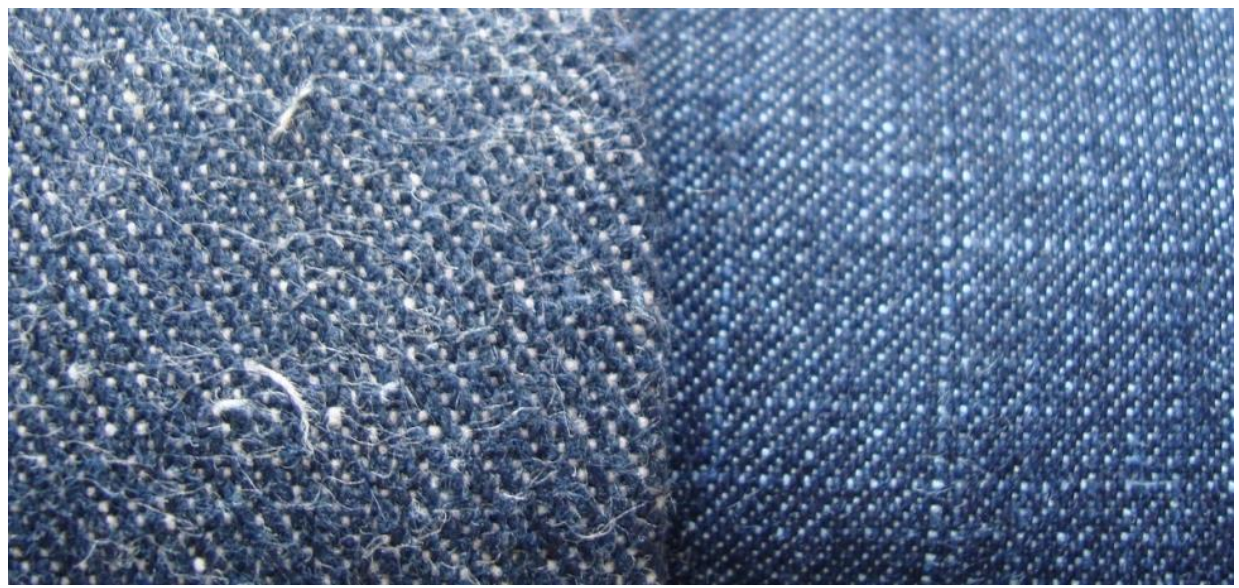

FIGURA 05 - Jeans reciclado (à esq.) e jeans convencional (à dir.) após teste de uso.

Elaborado pela autora, com base na pesquisa realizada.

\section{CONCLUSÃO}

A avaliação do uso dos protótipos indica que ambos, por terem a mesma composição, apresentam conforto termo-fisiológico semelhante. Nos demais parâmetros apresentados, pode-se dizer que o jeans CO/PET convencional apresenta maior conforto tátil e conforto estético que o jeans reciclado, sendo preferível do ponto de vista do usuário. Ademais, as informações fornecidas pelos fabricantes permitiram constatar que o jeans CO/PET convencional comporta maior amplitude de formas de lavar, passar e secar - ao contrário do jeans reciclado. Por outro lado, as restrições de temperatura e lavagem associadas à manutenção do jeans reciclado favorecem que o impacto ambiental na fase de uso possa ser inferior que o gerado pelo jeans convencional. Todavia os mesmos cuidados de manutenção destinados ao jeans reciclado podem ser dados também ao jeans CO/PET convencional, reduzindo assim seu impacto ambiental na fase de manutenção do produto. De uma maneira geral, embora o jeans reciclado esteja associado à redução do impacto ambiental nas fases de pré-produção, produção têxtil, uso e manutenção, o mesmo apresenta menor durabilidade e conforto que em relação ao jeans CO/PET convencional. 


\section{REFERÊNCIAS}

ABNT NBR ISO 3758. Têxteis: códigos de cuidados usando símbolos. 2006, 26 p.

ABREU, M. C. S. et al. Perfis estratégicos de conduta social e ambiental: estudos na indústria têxtil nordestina. Revista Gestão \& Produção, São Carlos, v. 15, n. 1, jan./abr. 2008, p. 159-172.

BAXTER, M. Projeto de produto: guia prático para o design de novos produtos. São Paulo: Blucher, 2000, $260 \mathrm{p}$.

BERTINI, J. Medição do conforto: o bom desempenho das mesclas poliéster/algodão. Rhodia-ster/M\&G, ano 10, n. 32, set. 2003, 4 p.

BILISIK, K., YOLACAN, G. Tensile and tearing properties of newly developed structural denim fabrics after abrasion. Fibres \& Textiles in Eastern Europe, v. 19, n. 5(88), 2011, p. 54-59.

BOTA, S., RATIU, M. Eco-textiles. In Annals of The International Scientific Symposium Innovative Solutions for Sustainable Development of Textiles Industry. Faculty of Textiles and Leatherwork, University of Oradea, Romania, 2008, p. 424-427.

BOVEA, M. D., PÉREZ-BELIS, V. A taxonomy of ecodesign tools for intergrating environmental requirements into the product design process. Journal of Cleaner Production, v. 20, 2012, p. 61-71.

CALLISTER, W. D. Ciência e engenharia de materiais: uma introdução. Rio de Janeiro: LTC, 2002, 359 p.

CATOIRA, L. Jeans, a roupa que transcende a moda. Idéias \& Letras, Aparecida-SP, 2006, $131 \mathrm{p}$.

CHATTOPADHYAY, R. Design of apparel fabrics: role of fibre, yarn and fabric parameters on its functional attributes. Journal of Textile Engineering, v. 54, n. 6, 2008, p. 19-190.

CLARCK, G.; KOSORIS, J.; HONG, L.; CRUL, M. Design for sustainability: current trends in sustainable product design and development. Sustainability, Paris, ano 1, 2009, p. 409-424.

COBRA, M. Marketing \& moda. São Paulo: Editora Senac São Paulo, Cobra Editora e marketing, 2007, $263 \mathrm{p}$.

COMAN, D., VRÎNCEANU, N., NEAGU, I. Eco-efficiency in the textile manufacturing activity by apposition environmental management. Annals of the University of Oradea Fascicle of Textiles - Leatherwork, v. 7, n. 1, 2011, p. 62-65.

DIOR, C. $O$ pequeno dicionário de moda. São Paulo: Martins, 2009, 136 p.

FIGUEIREDO, G. C., CAVALCANTE, A. L. B. L. Calça jeans - produtividade e possibilidades sustentáveis. Revista Projética, v. 1, n. 1, dez. 2010, p. 128-145.

FLETCHER, K. Sustainable fashion and textiles: design journeys. Londres e Washington DC: Earthscan, 2008, 239 p.

, GROSE, L. Moda \& sustentabilidade: design para mudança. São Paulo:

Editora Senac São Paulo, 2011, 192 p.

GIROLETTI, D. Fábrica convento disciplina. Imprensa Oficial, Belo Horizonte, 1991, 274 p.

$\mathrm{HU}, \mathrm{Y}$. A study of the sustainable fashion design in the process of use. International Journal of Arts and Commerce, v. 1, n. 4, 2012, p. 54-59.

IIDA, I. Ergonomia: projeto e produção. São Paulo: Edgard Blücher, 2005, 614 p. 
KALLIALA, E. M., NOUSIAINEN, P. Life cycle assessment: environmental profile of cotton and polyester-cotton fabrics. Research Journal, v. 1, n. 1, 1999, 13 p.

KAZAZIAN, T. Haverá a idade das coisas leves: design e desenvolvimento sustentável. Editora SENAC, São Paulo, 2005, 194 p.

LAITALA, K.; BOKS, C. Sustainable clothing design: use matters. Journal Design Research, v. 10, n. 1-2, 2012, p. 121-139.

LEÃO, M. D. et al. Controle ambiental na indústria têxtil: acabamento de malhas. Projeto Minas Ambiente, Belo Horizonte, 2002, 356 p.

LEITE, P. R. Logística reversa: meio ambiente e competitividade. Pearson Prentice Hall, São Paulo, 2009, 240 p.

LIPOVETSKY, G. O império do efêmero. São Paulo: Companhia das Letras, 2009, 352 p. MEKSI, N.; TICHA, M. B.; KECHIDA, M.; MHENNI, M. F. Using of eco-friendly $\alpha-$ hydroxycarbonyls as reducing agents to replace sodium dithionite in indigo dyeing process. Journal of Cleaner Production, v. 24, 2012, p. 149-158.

OZDIL, N. Stretch and bagging properties of denim fabrics containing different rates of elastane. Journal Fibres \& Textiles in Eastern Europe, v. 16, n. 1, jan./mar. 2008, p. 63-67.

PEZZOLO, D. B. Tecidos: história, tramas, tipos e usos. Editora Senac São Paulo, São Paulo, 2007, $324 \mathrm{p}$.

PORAV, V.; DOBLE, L. Methods for measuring garments comfort and influence factors in tactile comfort. Annals of the University of Oradea, Fascicle of Textiles Leatherwork, v. 1, n. 2, 2010, p. 118-122.

RUSU, L. Environment protection and the 21st century fibers. Annals of the University of Oradea Fascicle of Textiles - Leatherwork, v. 1, n. 1, 2010, p. 263-266.

SACHS, I. Estratégias de transição para do século XXI: desenvolvimento e meio ambiente. Studio Nobel, São Paulo, 1993, 104 p.

SELIG, P. M.; CAMPOS, L. M. S.; LERIPIO, A. A. Gestão ambiental. In: BATALHA, M. O. (org). Introdução à engenharia de produção. Elsevier, Rio de Janeiro, 2008, 312 p.

SLACK, N. et al. Administração da produção. Atlas, São Paulo, 1997, 754 p.

SMITH, G. G., BARKER, R. H. Life cycle analysis of a polyester garment. Resources, Conservation and Recycling, v. 14, 1995, p. 233-249.

SOUZA, M. C. C. Produção de algodão orgânico colorido: possibilidades e limitações. Informações Econômicas, São Paulo, v. 30, n. 6, jun. 2000, p. 91-98.

VIVEKANADAN, M. V.; RAJ, S.; SREENIVASAN, S.; NACHANE, R P. Parameters affecting warm-cool feeling in cotton denim fabrics. Indian Journal of Fibre \& Textile Research, v. 36, jun. 2011, p. 117-121. 